\title{
ANALISIS PENGARUH BUDAYA ORGANISASI DAN GAYA KEPEMIMPINAN TERHADAP KINERJA APARAT PENGAWAS INTERN PEMERINTAH DAERAH PROVINSI SULAWESI UTARA
}

\author{
Christony Maradesa ${ }^{1}$, Novi S. Budiarso ${ }^{2}$ \\ ${ }^{1}$ Jurusan Akuntansi, Fakultas Ekonomi, Universitas Prisma, Manado, Indonesia \\ ${ }^{2}$ Pendidikan Profesi Akuntansi, Fakultas Ekonomi dan Bisnis, Universitas Sam Ratulangi, Jl. Kampus Bahu, \\ Manado, 95115, Indonesia \\ E-mail : christonymaradesa@gmail.com
}

\begin{abstract}
This study aims to analyze the influence of organizational culture, leadership style to the performance of APIP. Data were obtained through questionnaires in North Sulawesi Province Inspectorate. Questionnaires were distributed to 39 respondents and were processed with multiple linear regression analysis method using SPSS version 24. The study consists of the dependent variable and independent variables. The dependent variable is the APIP performance, while the independent variables is organizational culture and leadership style. The result is Organizational Culture and Leadership Styles either simultaneously or partially affects the Performance of APIP.
\end{abstract}

Keywords: Organizational Culture, Leadership Style, Performance of APIP

\section{PENDAHULUAN}

Dalam lingkungan pemerintah fungsi monitoring struktur pengendalian internal dilakukan oleh satuan kerja audit internal yang dinamakan Aparat Pengawas Intern Pemerintah (APIP). Menurut Peraturan Pemerintah Republik Indonesia Nomor 60 Tahun 2008 tentang Sistem Pengendalian Intern Pemerintah (SPIP) menunjukkan bahwa salah satu peran APIP yang efektif adalah memelihara dan meningkatkan kualitas tata kelola penyelenggaraan tugas dan fungsi Instansi Pemerintah. Sesuai dengan Peraturan Pemerintah Nomor 60 Tahun 2008 tentang Sistem Pengendalian Intern Pemerintah (SPIP), pelaksanaan pengendalian intern dilaksanakan oleh Aparat Pengawas Intern Pemerintah (APIP). Berikut adalah badan yang termasuk dalam lingkup Aparat Pengawas Intern Pemerintah (APIP) : (1) Badan Pengawasan Keuangan dan Pembangunan (BPKP); (2) Inspektorat Jenderal; (3) Inspektorat Provinsi; dan (4) Inspektorat Kota.

Dalam menjalankan fungsi audit internal tersebut, maka APIP perlu didukung oleh kinerja auditornya. Audit internal memiliki peran penting dalam menjalankan fungsi pengawasan, sebagai penilai kecukupan struktur pengendalian intern, penilaian efektivitas struktur pengendalian intern, dan penilai kualitas kerja. Oleh karena itu seorang audit internal harus mampu menerapkan kemampuan, pengetahuan dan pengalaman (Arywarti Marganingsih, 2010) disamping independensi yang dibutuhkan dalam menghasilkan audit yang berkualitas. Fungsi audit internal akan efektif dan optimum apabila kinerja auditor ditentukan oleh perilaku auditor tersebut. Perilaku auditor tersebut dapat terlihat dari komitmennya pada organisasi dan motivasinya untuk meningkatkan kinerjanya.

Penelitian di Indonesia yang menggunakan variabel-variabel di atas pada umumnya menggunakan sampel penelitian di Kantor Akuntan Publik (KAP) dan industri khususnya manufaktur (Dwi Maryani dan Supomo, 2002; Darlis, 2002; Ratnawati, 2002; Lekatompessy, 2005; Prasita dan Adi, 2007 dalam Arywarti Marganingsih, 2010). Untuk penelitian di lingkungan Aparat Pengawas Intern Pemerintah pernah di lakukan di Lembaga Pemerintah Non Departemen (Arywarti Marganingsih, 2010). Berdasar data tersebut penulis merasa perlu 
untuk melakukan penelitian serupa di lingkungan Aparat Pengawas Intern Pemerintah Daerah Provinsi Sulawesi Utara, untuk mengetahui apakah Budaya Organisasi dan Gaya Kepemimpinan mempunyai pengaruh atau tidak pada lingkungan Aparat Pengawas Intern Pemerintah Daerah Provinsi Sulawesi Utara.

\section{TINJAUAN PUSTAKA}

\subsection{Kinerja}

Kinerja merupakan tindakan-tindakan atau pelaksanaan-pelaksanaan tugas yang dapat diukur. As'ad 2004 dalam Wilhelmus Andiyanto 2011 memberikan batasan bahwa kinerja sebagai kesuksesan seseorang dalam melaksanakan pekerjaan. Sedangkan penulis lain Byars, Lllyod and Rue 2006 dalam Rizka Pratiwi, 2014 mendefinisikan kinerja merupakan derajat penyelesaian tugas yang menyertai pekerjaan seseorang. Kinerja adalah yang merefleksikan seberapa baik seseorang individu memenuhi permintaan pekerjaan. Berdasarkan definisidefinisi di atas, menunjukan bahwa kinerja merupakan hasil yang bersifat kuantitatif dan kualitatif.

\subsection{Budaya Organisasi}

Budaya organisasi adalah nilai-nilai dan keyakinan (belief) yang dimiliki oleh anggota organisasi, yang dimanifestasikan dalam bentuk norma-norma perilaku para individu atau kelompok organisasi yang bersangkutan (pendekatan dimensi praktik) (Tjahjaning Poerwati, 2001). Budaya organisasi adalah seperangkat nilai yang mengendalikan interaksi antara satu individu dalam organisasi dengan individu dalam organisasi, atau organisasi lain sebagai pemasok, dan anggota masyarakat yang dilayani. Budaya organisasi dibentuk oleh para individu, dalam organisasi, etika organisasi yang dianut, hak kepegawaian yang diberikan kepada tiap pegawai dan juga jenis struktur organisasi itu sendiri. Budaya organisasi juga membentuk dan mengendalikan perilaku dalam keorganisasian. Budaya organisasi mempengaruhi cara individu merespons dan menafsirkan segala situasi dan permasalahan yang ada di dalam organisasi.

\subsection{Gaya Kepemimpinan}

Kepemimpinan merupakan kemampuan mempengaruhi suatu kelompok kearah pencapaian tujuan atau suatu usaha menggunakan suatu gaya mempengaruhi dan tidak memaksa untuk memotivasi individu dalam mencapai tujuan (Rachmawati, 2006). Seorang pemimpin dapat melalukan berbagai cara dalam kegiatan mempengaruhi dan memotivasi bawaahannya atau orang lain agar melakukan tindakan-tindakan yang selalu terarah terhadap pencapaian tujuan organisasi (Sarita dan Agustia, 2009).

\section{METODE PENELITIAN}

\subsection{Tempat dan Waktu Penelitian}

Penelitian ini dilaksanakan pada Inspektorat Pemerintah Provinsi Sulawesi Utara. Dilaksanakan dari bulan Agustus - Oktober 2016.

\subsection{Prosedur Penelitian}

Prosedur penelitian yang di lakukan peneliti dalam penelitian ini adalah yang pertama mengajukan permohonan ijin penelitian terlebih dahulu kepada instansi terkait yaitu Inspektorat Pemerintah Provinsi Sulawesi Utara. Setelah mendapat ijin barulah peneliti menyebarkan kuesinor pada objek penelitian yaitu Aparat Pengawas Intern Pemerintah.

\subsection{Populasi}

Populasi dalam penelitian ini adalah auditor internal yang berada di lingkungan Aparat Pengawasan Intern Pemerintah Daerah Provinsi Sulawesi Utara Sebanyak 39 auditor internal.

\subsection{Sampel}


Metode pemilihan sampel adalah metode purposive sampling, dimana purposive sampling adalah prosedur untuk mendapatkan unit sampel dengan didasarkan pada kriteria tertentu (Arywarti Marganingsih, 2010). Adapun kriteria tersebut yaitu : (1) Auditor Pemerintah yang melaksanakan pekerjaan di bidang auditing; dan (2) Auditor Pemerintah yang mempunyai latar belakang pendidikan minimal Strata 1. Dalam penelitian ini peneliti mengambil auditor internal yang ada di lingkungan Pemerintah Provinsi Sulawesi Utara. Sehingga sampel dalam penelitian ini berjumlah 39 auditor internal.

\section{HASIL ANALISIS DAN PEMBAHASAN}

\subsection{Pengolahan Data}

Langkah-langkah yang dilakukan dalam pengujian ini yaitu dengan memasukkan (input) data variabel ke dalam program Microsoft Excel, kemudian ditransfer ke bagian Data View dalam Software Program SPSS Version 24.0 untuk dilakukan pengolahan data yang kemudian dianalisis lebih lanjut.

\subsection{Pengujian Validitas}

Pengujian validitas variabel Budaya Organisasi(X1), Gaya Kepemimpinan (X2), Kinerja APIP (Y) dengan menggunakan Software SPSS Version 24.0 sebagai berikut.

Tabel 1 Tabel Uji Validitas Budaya Organisasi

\begin{tabular}{cc}
\hline N & Corrected Item - Total Item Correlation \\
\hline P1 &, 741 \\
P2 &, 781 \\
P3 &, 780 \\
P4 &, 736 \\
\hline
\end{tabular}

Sumber : Data Penelitian Telah Diolah, 2016

Tabel 1, P1 menunjukan nilai correlation sebersar 0,741, P2 menunjukan nilai correlation sebesar $0,781, \mathrm{P} 3$ menunjukan nilai correlation sebesar 0,780 , P4 menunjukan nilai correlation sebesar 0,736 .Dengan demikian seluruh item adalah valid, karena nilai Correlation (X1) lebih besar dari r Tabel Data X1 adalah valid.

Tabel 2 Tabel Uji Validitas Gaya Kepemimpian

\begin{tabular}{lc}
\hline N & Corrected Item - Total Item Correlation \\
\hline P1 &, 942 \\
P2 &, 903 \\
P3 &, 924 \\
P4 &, 835 \\
P5 &, 931 \\
P6 &, 890 \\
P7 &, 910 \\
P8 &, 762 \\
P9 &, 937 \\
P10 &, 846 \\
P11 &, 936 \\
P12 &, 837 \\
P13 &, 896 \\
P14 &, 942 \\
P15 &, 881 \\
\hline
\end{tabular}

Sumber : Data Penelitian Telah Diolah, 2016 
Tabel 2 P1 menunjukan correlation sebersar 0,942, P2 menunjukan nilai correlation sebesar 0,903, P3 menunjukan nilai correlation sebesar 0,924, P4 menunjukan nilai correlation sebesar 0,835, P5 menunjukan nilai correlation sebesar 0,931, P6 menunjukan nilai correlation 0,890, P7 menunjukan nilai correlation 0,910 , P8 menunjukan nilai correlation 0,762 , P9 menunjukan nilai correlation 0,937 , P10 menunjukan correlation 0,846, P11 menunjukan nilai correlation 0,936 , P12 menunjukan nilai correlation $0,837, \mathrm{P} 13$ menunjukan nilai correlation 0,896, P14 menunjukan nilai correlation 0,942, P15 menunjukan nilai correlation 0,881 .Dengan demikian seluruh item adalah valid, karena nilai Correlation (X2) lebih besar dari r Tabel. Data X2 adalah valid.

Tabel 3 Tabel Uji Validitas Kinerja APIP

\begin{tabular}{cc}
\hline N & Corrected Item - Total Item Correlation \\
\hline P1 &, 899 \\
P2 &, 907 \\
P3 &, 835 \\
P4 &, 915 \\
P5 &, 800 \\
P6 &, 911 \\
P7 &, 911 \\
P8 &, 871 \\
P9 &, 897 \\
P10 &, 786 \\
\hline
\end{tabular}

\section{Sumber : Data Penelitian Telah Diolah, 2016}

Tabel 3, P1 menunjukan correlation sebersar 0,899, P2 menunjukan nilai correlation sebesar 0,907, P3 menunjukan nilai correlation sebesar 0,835, P4 menunjukan nilai correlation sebesar 0,915, P5 menunjukan nilai correlation sebesar 0,800, , P6 menunjukan nilai correlation 0,911, P7 menunjukan nilai correlation 0,911, P8 menunjukan nilai correlation 0,871 , P9 menunjukan nilai correlation 0,897 , P10 menunjukan correlation 0,786, Dengan demikian seluruh item adalah valid, karena nilai Correlation (Y) lebih besar dari $r$ Tabel. Data Y adalah valid.

\subsection{Pengujian Reliabilitas}

Metode pengujian reliabilitas adalah dengan menggunakan analisis Reliability melalui metode Cronbach Alpha yang diukur berdasarkan skala alpha 0 sampai dengan 1. Ukuran kemantapan alpha dapat diinterpretasi seperti pada Tabel 4 berikut.

Tabel 4

Tingkat Reliabilitas Berdasarkan Nilai Alpha

\begin{tabular}{|c|c|}
\hline Alpha & Tingkat Reliabilitas \\
\hline $0,00 \mathrm{~s} / \mathrm{d} 0,20$ & Kurang Reliabel \\
\hline$>0,20 \mathrm{~s} / \mathrm{d} 0,40$ & Agak Reliabel \\
\hline$>0,40 \mathrm{~s} / \mathrm{d} 0,60$ & Cukup Reliabel \\
\hline$>0,60 \mathrm{~s} / \mathrm{d} 0,80$ & Reliabel \\
\hline$>0,80 \mathrm{~s} / \mathrm{d} 1,00$ & Sangat Reliabel \\
\hline
\end{tabular}

Setelah data diolah dengan menggunakan bantuan Software SPSS Version 24.0 untuk menguji tingkat reliabilitas, maka output yang dihasilkan dapat dilihat pada yang dapat ditunjukkan pada Tabel 5 berikut. 


\begin{tabular}{cc}
\hline \multicolumn{2}{c}{ Tabel 5 Uji Reliabilitas } \\
\hline Variabel & Cronbach's Alpha \\
\hline Y &, 971 \\
X1 &, 886 \\
X2 &, 981 \\
\hline
\end{tabular}

Sumber : Data Penelitian Telah Diolah, 2016

Dari pengujian tingkat reliabilitas seperti yang disajikan pada tabel 4.10 maka pada bagian cronbach's alpha $\mathrm{Y}=0,971$, cronbach's alpha $\mathrm{X} 1=0,886$, cronbach's alpha X2=0,981. Jadi oleh karena nilai cronbach alpha hasil output terletak diantara $>0,80-1,00$ (tabel 4.3.1) sehingga tingkat reliabilitasnya adalah sangat reliable.

\subsection{Hasil Uji $\mathbf{F}$ dan $t$}

\subsubsection{Uji F}

Tabel 6. Uji F

\begin{tabular}{lrrrrr}
\hline \multicolumn{1}{c}{ Model } & Sum of Square & df & Mean Square & F & Sig. \\
\hline Regresion & 495,802 & 2 & 247,901 & 56,893 &, 000 \\
Residual & 156,864 & 36 & 4,357 & & \\
Total & 652,667 & 38 & & & \\
\hline
\end{tabular}

Dari Tabel 6, dapat diketahui hasil $\mathrm{F}_{\text {hitung }}=56,893$ dan $\mathrm{F}_{\text {tabel }}$ dengan tingkat keyakinan sebesar 95\% dimana df 1 (3-1) dan df 2 (39-2-1) adalah sebesar 3,259 dengan hasil signifikan 0,000. Jadi dapat dilihat bahwa $F_{\text {hitung }}>F_{\text {tabel }}$ maka dapat variabel Budaya Organisasi dan Gaya Kepemimpinan berpengaruh terhadap Kinerja. APIP.

\subsubsection{Uji t}

Tabel 7. Hasil Uji t

\begin{tabular}{llllllll}
\hline \multicolumn{1}{c}{ Model } & $\begin{array}{c}\text { Unstandarized } \\
\text { B }\end{array}$ & $\begin{array}{c}\text { Coeffisent } \\
\text { Standar } \\
\text { Error }\end{array}$ & $\begin{array}{c}\text { Standarized } \\
\text { Coefisent } \\
\text { Beta }\end{array}$ & $\mathbf{t}$ & Sig. & Tolerance & VIF \\
\hline $\begin{array}{l}\text { Budaya } \\
\text { Organisasi }\end{array}$ &, 489 &, 223 &, 461 & 2,188 &, 035 &, 150 &, 6652 \\
$\begin{array}{l}\text { Gaya } \\
\text { Kepemimpinan }\end{array}$ &, 505 &, 249 &, 428 & 2,031 &, 050 &, 150 &, 6652 \\
\hline
\end{tabular}

Berdasarkan nilai statistik pada hasil analisis regresi linier berganda pada Tabel 7, dapat dilihat bahwa $t_{\text {hitung }}$ variabel budaya organisasi (X1) diperoleh angka 2,188>t $t_{\text {tabel }} 2,028$ Berdasarkan nilai statistik pada hasil analisis regresi linier berganda, dapat dilihat bahwa

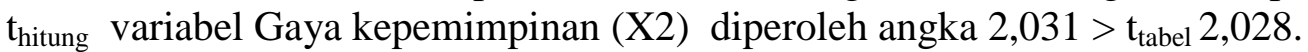

\subsection{Pembahasan}

\subsubsection{Pengaruh Budaya Organisasi terhadap Kinerja APIP}

Hasil pengujian statistik menunjukkan $t_{\text {hitung }}$ variabel budaya organisasi (X1) diperoleh angka 2,188>t $\mathrm{t}_{\text {tabel }} 2,028$ maka dapat dinyatakan secara parsial (variabel $\mathrm{X}_{1}$ ) budaya organisasi berpengaruh terhadap kinerja APIP (variabel Y). Hasil tersebut dapat dipahami bahwa untuk meningkatkan kinerja audit, seorang auditor sangat bergantung pada budaya organisasi. Jika dalam instansi inspektorat memiliki budaya organisasi yang baik hal itu akan meningkatkan kinerja auditor internal yang dapat menghasilkan kualitas audit yang baik. 


\subsubsection{Pengaruh Gaya kepemimpinan terhadap kinerja APIP}

Hasil pengujian statistik menunjukkan thitung variabel gaya kepemimpinan (X1) diperoleh angka 2,031 > tabel 2,028 maka dapat ecara parsial (variabel X2) gaya kepemimpinan berpengaruh terhadap kinerja APIP (variabel Y). Pemimpin tim berkewajiban mempengaruhi anggota tim yang dibawahinya agar mereka tetap melaksanakan tugas dengan baik, memiliki dedikasi terhadap instansi dan tetap merasa berkewajiban untuk mencapai tujuan instansi.

\section{KESIMPULAN DAN SARAN}

Penelitian ini bertujuan untuk mengetahui pengaruh budaya organisasi, gaya kepemimpinan, terhadap kinerja auditor internal di lingkungan inspektorat provinsi Sulawesi utara. Berdasarkan hasil penelitian maka dapat diambil kesimpulan sebagai berikut.

1. Budaya organisasi berpengaruh terhadap kinerja inspektorat. Hasil tersebut dapat dipahami bahwa untuk meningkatkan kinerja audit, seorang auditor sangat bergantung pada budaya organisasi.

2. Gaya Kepemimpinan berpengaruh terhadap kinerja inspektorat. Hasil ini membuktikan Pemimpin tim berkewajiban mempengaruhi anggota tim yang dibawahinya agar mereka tetap melaksanakan tugas dengan baik, memiliki dedikasi terhadap instansi dan tetap merasa berkewajiban untuk mencapai tujuan instansi.

\section{DAFTAR PUSTAKA}

Arywarti Marganingsih. 2010. Analisis Variabel Anteseden Perilaku Auditor Intenal Dan Konsekuensinya Terhadap Kinerja: Studi Empiris pada Auditor di Lingkungan Aparat Pengawasan Intern Pemerintah - Lembaga Pemerintah Non Departemen. Jurnal Akuntansi dan Keuangan Indonesi. Vol. 7. No. 1.

As'ad. 2004. Psikologi Industri Seri Umum. Sumber Daya Manusia. Edisi 4. Penerbit Liberty. Yoygyakarta.

Byars, Lllyod L and Rue 2006. "Human Resource Management, 8 edition." MCGraw-Hill, Irwin.

Dalimunthe. 2009. Pengaruh Budaya Organisasi Terhadap Kinerja Pegawai (Studi Pada Dinas Informasi Kommunikasis Dan Pengelolaaan Data Elektronik Kota Medan). Skripsi Universitas Sumatera Utara. Medan.

Darlis. 2002. Analisis Pengaruh Komitmen Organisasional dan Ketidakpastian Lingkungan Terhadap Hubungan Antara Partisipasi Anggaran dengan Senjangan Anggaran. Jurnal Riset Akuntansi. Vol. 5. No. 1.

Duwi Priyatno. 2016. SPSS. 22 Pengolah Data Terpraktis. Penerbit Andi. Yogyakarta.

Dwi Maryani dan Supomo. 2001. Studi empiris pengaruh kepuasan kerja terhadap kinerja individual. Jurnal Bisnis dan Akuntansi. Vol. 3. No.1.

Fajar Kurniadi. 2012. Pengaruh Kompensasi Dan Motivasi Terhadap Kinerja Karyawan Di Apotek Berkah. Skripsi Universitas Widyatama. Bandung.

Lekatompessy. 2005. Analisis Variabel Anteseden dan Konsekuensi OrganizationalProfessional Conflict Akuntan di KAP dan Industri. Jurnal Riset Akuntansi. Vol. 8. No. 2.

Prasita dan Adi, 2007. Pengaruh Kompleksitas Audit dan Tekanan Anggaran Waktu Terhadap Kualitas Audit dengan Moderasi Pemahaman Terhadap Sistem Informasi. Jurnal Ekonomi dan Bisnis. Vol. XIII., No. 1.

Rachmawati, 2006. Pengaruh Motivasi Kerja, Kemampuan Kerja dan Gaya Kepemimpinan Terhadap Kinerja Karyawan Pada Badan Kesatuan Bangsa dan Perlindungan 
Masyarakat Propinsi Jawa Tengah. Jurnal Ilmu Administrasi dan Kebijakan Publik. Vol. 3. No. 1.

Rizka Pratiwi. 2014. Pengaruh Budaya Organisasi Terhadap Kinerja Pegawai Pada Kantor Pelayanan Kekayaan Negara Dan Lelang Makasar. Skripsi Universitas Hasanuddin. Makasar.

Sarita dan Agustia. 2009. Pengaruh Gaya Kepemimpinan Situasional, Motivasi Kerja, Locus of Control, Terhadap Kepuasan Kerja dan Prestasi Kerja Auditor. SNA XII. Palembang

Tjahjaning Poerwati. 2001. Pengaruh Partisipasi Penyusunan Anggaran Terhadap Kinerja Manajerial : Budaya Organisasi Dan Motivasi Sebagai Variabel Moderating. Tesis Universitas Diponegoro. Semarang.

Wilhelmus Andiyanto. 2011. Pengaruh Motivasi Kerja Dan Kepemimpinan Terhadap Kinerja Pegawai Pada Badan Keluarga Berencana Dan Pemberdayaan Perempuan Kabupaten Manggarai- Flores Nusa Tenggara Timur. Skripsi Universitas Diponegoro. Semarang. 